\title{
ANÁLISE DA TEMPERATURA DE SUPERFÍCIE E SUA CORRELAÇÃO COM A COBERTURA VEGETAL E TIPOS DE USO NA MICROBACIA DO RIO DA BATATEIRAS, CRATO-CE.
}

\author{
Cicera Celiane Januário da Silva ${ }^{(a)}$, Joyce Ferreira Gomes ${ }^{(b)}$, Juliana Maria Oliveira Silva ${ }^{(c)}$ \\ (a) Graduanda em Geografia e bolsista de Iniciação Científica - PIBIC/URCA, celianejanuario@ gmail.com, \\ (b) Estagiária no Laboratório de Análise Geoambiental - LAGEO, URCA, joyceferreira234@yahoo.com, \\ (c) Orientadora, Professora do Departamento de Geociências/URCA, juliana.oliveira@urca.br
}

\section{Eixo: Climatologia em diferentes níveis escalares: mudanças e variabilidades.}

\begin{abstract}
Resumo
O presente trabalho visa fazer uma análise de temperatura das diferentes superfícies na microbacia do Rio da Batateiras, localizada na cidade do Crato-CE e correlacionar com os diferentes tipos de cobertura vegetal deste local. A área ainda necessita de pesquisas mais abrangentes no que se refere a temperatura, porque observa-se um rápido crescimento em direção a encosta da Chapada do Araripe, onde se localiza o alto curso do rio, o que poderá alterar as condições climáticas favorecidas pelo relevo e pelas fontes de água que surgem na encosta, dentre elas, a nascente do rio da Batateiras, considerada a de maior vazão. A temperatura através do mapa da estimativa da temperatura de superfície na microbacia do rio da Batateiras variou desde $26.85 \mathrm{C}^{\circ}$ e $28.36 \mathrm{C}^{\circ}$ na área localizada próxima à Chapada do Araripe, o alto curso do rio, até $31.76 \mathrm{C}^{\circ}$ e $34.31 \mathrm{C}^{\circ}$ distribuídas no alto, médio e baixo curso da microbacia.
\end{abstract}

Palavras-chave: Estimativa de temperatura, imagens de satélite, Crato-CE.

\section{Introdução}

O sensoriamento remoto define-se como um conjunto de procedimentos destinados à obtenção de imagens ou outros tipos de dados por meio da coleta de energia eletromagnética emitida ou refletida pela superfície terrestre, através de sensores acoplados nos mais variados níveis de aquisição. Esta técnica destaca-se por disponibilizar a visualização de um recorte espacial de diferentes escalas, além de fornecer dados do infravermelho termal (FLORENZANO, 2011).

O objetivo deste trabalho é estimar a temperatura de superfície da microbacia do rio da Batateiras/Crato CE (figura 01), para o ano de 2016, utilizando-se imagens do satélite LANDSAT 8TM, banda 10 (termal). O rio da Batateiras faz parte da sub-bacia do rio Salgado, possui suas nascentes na Chapada do Araripe e durante seu percurso drena a cidade do Crato, tendo como um dos principais afluentes o rio Granjeiro. O rio da Batateiras no seu alto e médio curso possui uma unidade de conservação, o Parque Estadual do Sítio Fundão, fundado em 2008. 
A temperatura de superfície diz respeito ao fluxo de calor dado em função da energia que chega e sai do corpo, sendo de suma importância para o entendimento das interações entre a superfície terrestre e a atmosfera (STEINKE et al, 2010).

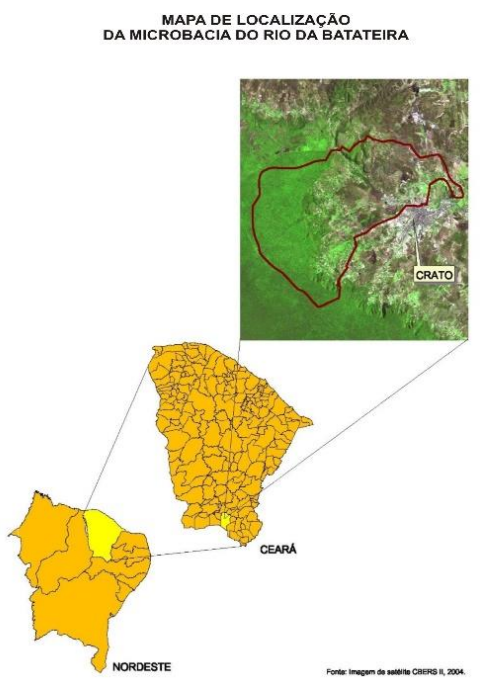

Figura 01-Localização da área de estudo. Fonte: Magalhães (2008)

\section{Metodologia}

Para se alcançar os resultados, a pesquisa foi dividida por etapas: levantamento bibliográfico apoiado em leituras de autores como Gartland (2010), Pereira et al (2012), Steinke et al (2010), Florenzano (2011) e outros. Caracterização da área de estudo. Para esta etapa se consultará trabalhos já existentes sobre a microbacia baseada em Magalhães (2006). Seleção das imagens termais que são adquiridas através do catálogo de imagens do Serviço Geológico Americano. A imagem selecionada para a área de estudo foi dada a partir da imagem de satélite LANDSAT 8 (banda 10), na passagem do dia 14/11/2016. Para a confecção do mapa de estimativa de temperatura adotou-se as seguintes etapas: 1) conversão dos tons de cinza (DN's) em valores de temperatura de superfície utilizando a ferramenta "raster calculator" do software Arcgis 10.2, utilizando-se os parâmetros fixos de conversão de níveis de cinza da imagem (NC) para radiância, depois para temperatura Kelvin e finalmente para graus Celsius $\left({ }^{\circ} \mathrm{C}\right)$ conforme as fórmulas de calibração disponíveis no site do Serviço Geológico Americano. O mapeamento do uso e ocupação da área ainda está sendo feito, o mesmo será realizado no software QGIS 2.10 disponibilizado livremente. E o levantamento de campo, uma das etapas mais importantes que será realizado na pesquisa, pois poderá 
certificar os resultados do mapeamento e atualizar as informações referentes ao uso e ocupação e vegetação.

\section{Resultados e Discussões}

Analisando o mapa de estimativa de temperatura da microbacia do rio da Batateiras/Crato-CE (figura 02), percebe-se que as temperaturas variaram entre $26.8 \mathrm{C}^{\circ}$ e $28.3 \mathrm{C}^{\circ}$ representada pelas tonalidades de azul mais escuro, até $31.7^{\circ} \mathrm{C}$ e $34.31^{\circ} \mathrm{C}$ com cores avermelhadas, distribuídas em setores do alto, médio e baixo curso da microbacia.

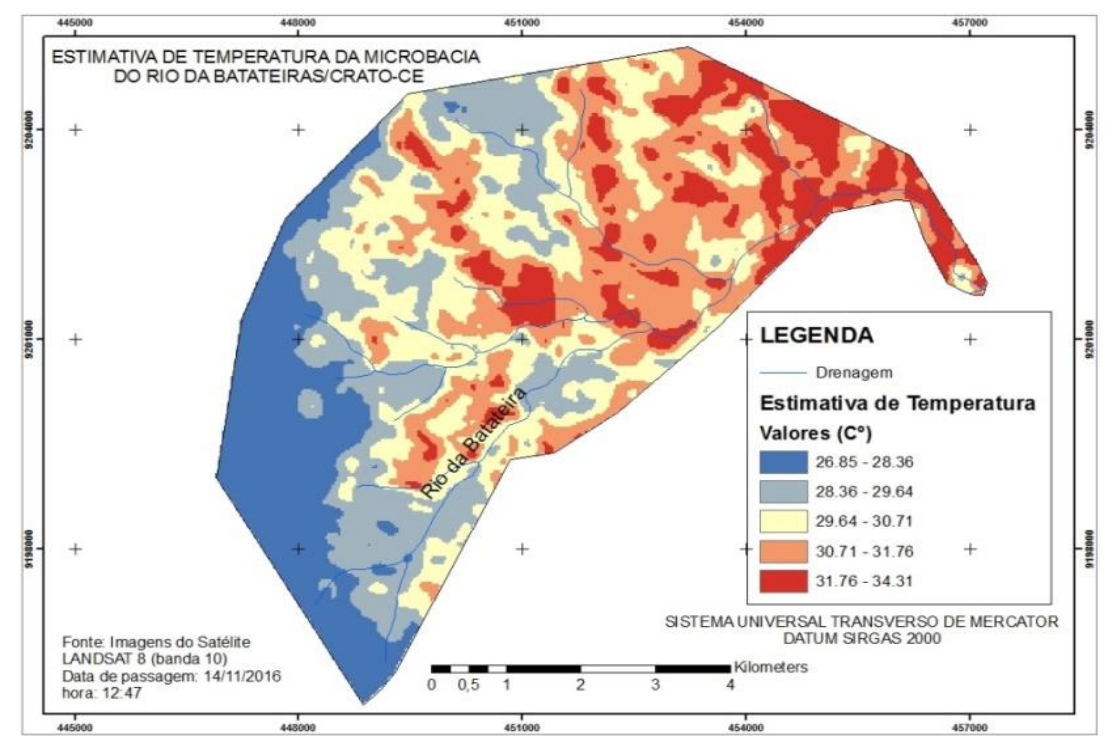

Figura 02 - Mapa da estimativa de temperatura da microbacia do rio da Batateiras/Crato-CE. Fonte: SILVA, J. M. O.

A classe com temperaturas menores $\left(26.8 \mathrm{C}^{\circ}\right.$ e $\left.28.3 \mathrm{C}^{\circ}\right)$ correspondem ao local onde há presença maior de cobertura vegetal, encontrando no topo e na encosta da Chapada do Araripe, em que o rio tem suas nascentes. Segundo Magalhães (2006) os principais tipos de vegetação na área são de características da mata úmida e sub-úmida, mata seca, cerrado entre outras, circunvizinhas a mata ciliar mata presentantes do cerradontre si em termos de composição. Ainda segundo a autora a ocorrência da vegetação mais conservada nesses dois ambientes, deve-se ao difícil acesso as nascentes do rio, que se localizam na escarpa da Chapada do Araripe, o que dificulta a especulação imobiliária, e também por essa área ser considerada legalmente uma APP (Área de Preservação Permanente).

De acordo com os diferentes tipos de ocupações nesta área, a temperatura vai aumentando pelos fatores da urbanização, existência do solo exposto e pouca vegetação, chegando a atingir uma temperatura mais 


\begin{tabular}{|c|c|}
\hline $\begin{array}{l}\text { XVII Simpósio Brasileiro } \\
\text { de Geografia Fisica Aplicada }\end{array}$ & $\begin{array}{l}\text { OS DESAFIOS DA GEOGRAFIA FÍSICA NA FRONTEIRA DO CONHECIMENTO } \\
\text { Instituto de Geociências - Unicamp }\end{array}$ \\
\hline $\begin{array}{l}\text { I Congresso Nacional } \\
\text { de Geografia Física }\end{array}$ & $\begin{array}{l}\text { Campinas - SP } \\
28 \text { de Junho à } 02 \text { de Julho de } 2017\end{array}$ \\
\hline
\end{tabular}

quente até $34.31 \mathrm{C}^{\circ}$. Conforme Pereira et al (2012) isso indica que a cobertura do solo apresenta padrões de comportamento diferenciados de absorção de energia, produção de calor e reflectância. Na área do Sítio Fundão, nas imediações da indústria da Grendene (figuras 03), por ser uma unidade de conservação e com densidade maior de cobertura vegetal perto do rio, a temperatura variou entre $28.36^{\circ} \mathrm{C}$ e $29.64^{\circ} \mathrm{C}$.

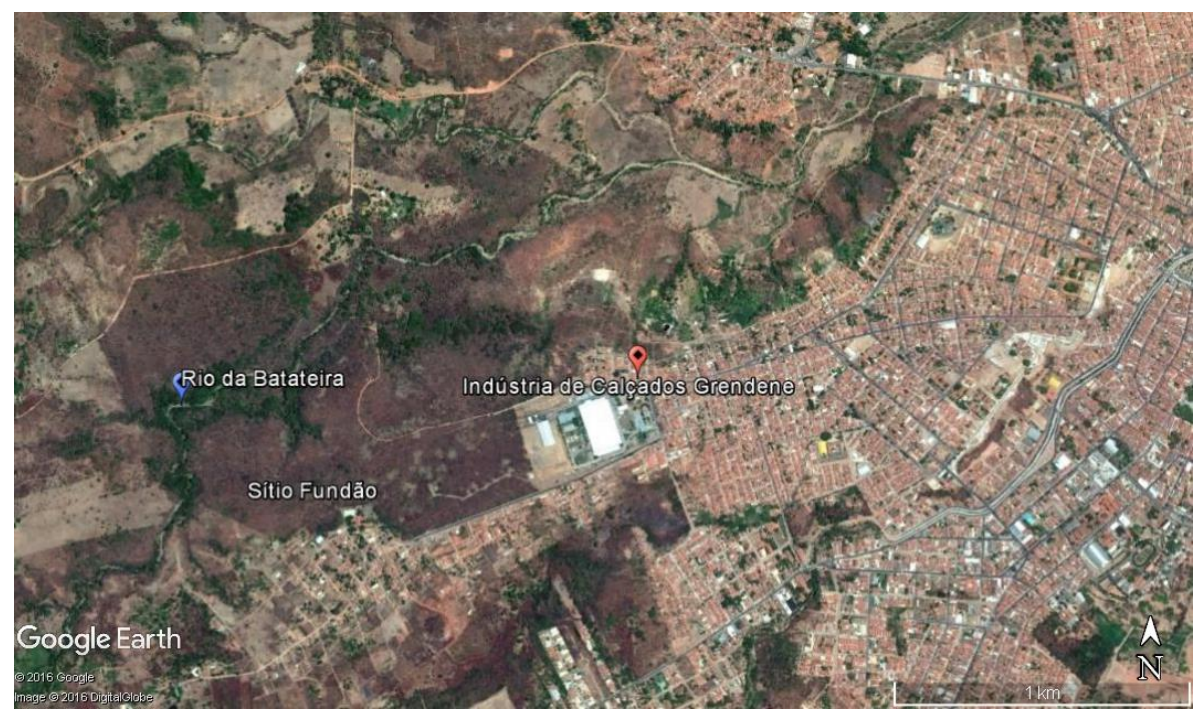

Figura 03 - Localização do Sítio Fundão e da Indústria de Calçados Grendene no alto curso do Rio da Batateira, município do Crato/CE. Fonte: Google Earth, 2017.

Segundo Gartland (2010), árvores e vegetação trazem muitos benefícios às comunidades, inclusive a melhoria do conforto, redução de consumo de energia, retirada do dióxido de carbono $\mathrm{CO}_{2}$ do ar, redução da poluição do ar e redução de enchentes.

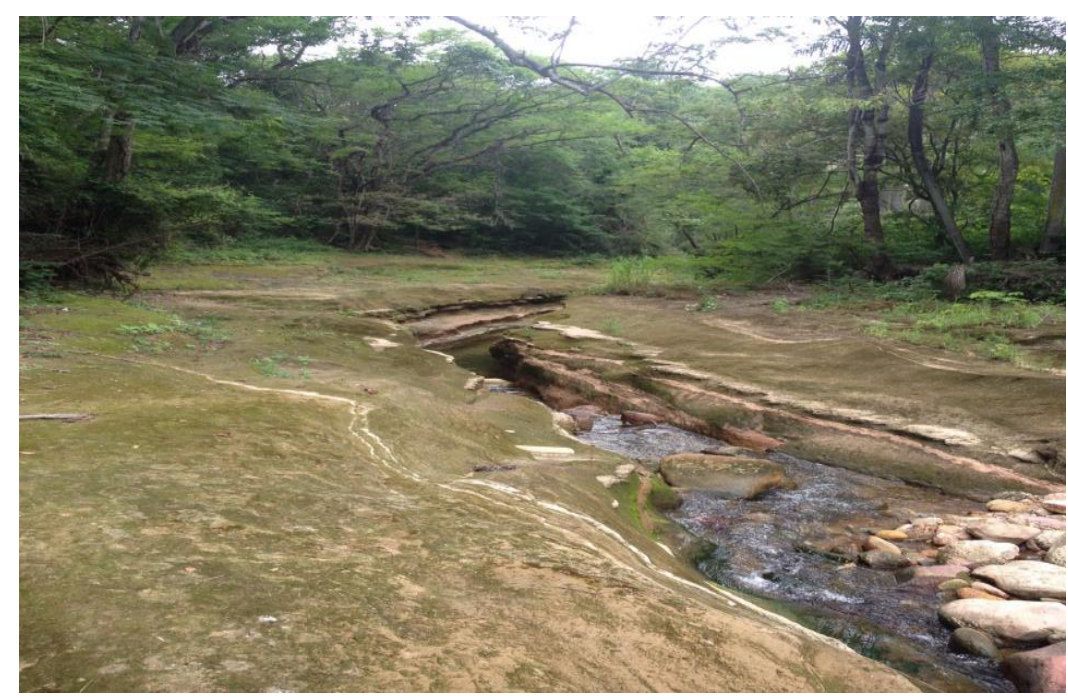

Figura 04 - Rio da Batateira, Crato/CE. Fonte: SILVA, J. M. O. 


\section{Considerações Finais}

A realização deste trabalho é mais uma contribuição de estudo para a área no que se refere a temperatura,

pois esse fenômeno é influenciado por vários fatores, dentre eles, a vegetação, solo exposto, asfalto e entre outros. Esses fatores interferem diretamente nos valores de temperatura, alterando a sensação térmica do ambiente. A finalização do mapeamento de uso e ocupação oferecerá um suporte maior para a interpretação dos diferentes valores de temperatura encontrada e poderá subsidiar discussões sobre a importância do uso do sensoriamento remoto para os estudos climáticos.

\section{Bibliografia}

FLORENZANO, T.G. Iniciação em Sensoriamento Remoto. São Paulo: Oficina de Texto, 2011. $3^{\text {a }}$ ed. Ampliada e atualizada.

GARTLAND, Lisa. Ilhas de calor: como mitigar zona de calor em áreas urbanas. São Paulo: Oficina de textos, 2010.

MAGALHÃES, A. O. Análise ambiental do alto curso da microbacia do rio da Batateiras no município de Crato/CE: subsídios ao Zoneamento Ecológico-Econômico. Universidade Federal do Ceará. 2006. (Dissertação de Mestrado)

PEREIRA, C. C.; MARIANO, Z. F.; WACHHOLZ, F.; CABRAL, J. B. P. Análise da temperatura de superfície e do uso da terra e cobertura vegetal na bacia Barra dos Coqueiros (Goiás). Revista Geonorte, v. 1, p. 1243-1255, 2012.

SILVA, J. M. O. Uso do sensoriamento remoto para a estimativa da temperatura de superfície na microbacia do rio Granjeiro - Crato/Ceará. Geosaberes: Revista de Estudos Geoeducacionais. , v.06, p.130 - 144, 2015.

STEINKE, V. A.; STEINKE, E. T.; SAITO, C. H. Estimativa da temperatura de superfície em áreas urbanas em processo de consolidação: reflexões e experimento em Planaltina-DF. Revista Brasileira de Climatologia, ano, 6, 2010. P. 37-56. 